\title{
المساهمة فى الغطة العلاجية لمريض القدم السكرى من خلال تصميم وتنفيذ جورب معالج بالقسط الهندى
}

\section{Contribution to diabetic foot treatment strategy through design and performance of Indian Costus treated Sock}

$$
\begin{aligned}
& \text { د/ياسمين أحمد الكحكى } \\
& \text { مدرس الملابس والنسيج } \\
& \text { كلية النربية النوعية- جامعة أسيوط ولندانيو }
\end{aligned}
$$

\author{
د/هلال فؤاد حتة حسين \\ مدرس الميكروبيولوجيا الطبية والمناعة \\ كلية الطب - جامعة أسيوط
}

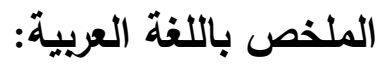

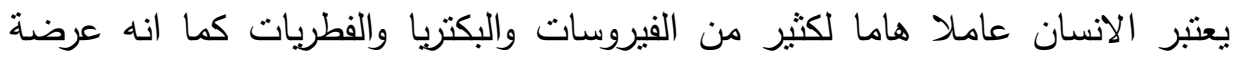

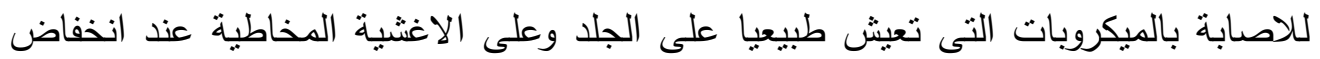

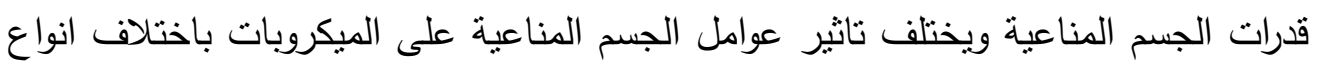

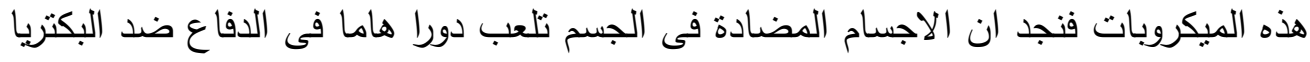

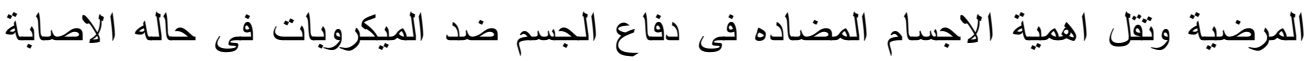
بالفيروسات.

هدف البحث الى دراسة انواع البكتريا التى تتمو على تقيحات الققد السكرى واستخدام

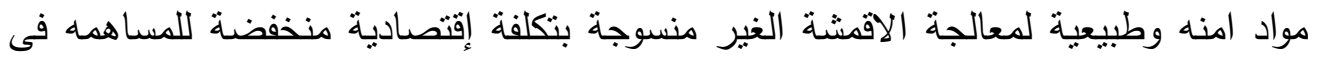

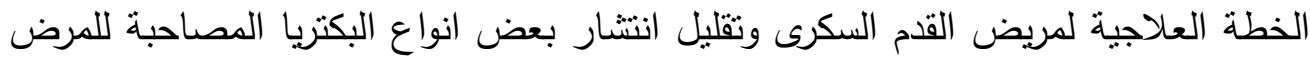

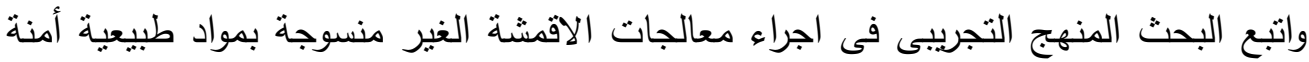

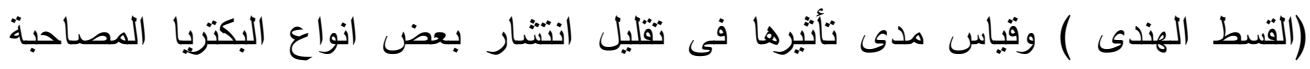

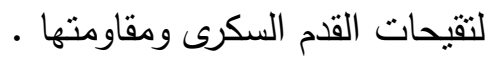

وتوصل البحث الى تصميم وتتفيذ جورب من الاقمشة الغيرمنسوجة والمعالجة بالقسط

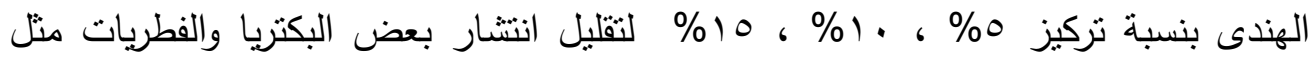

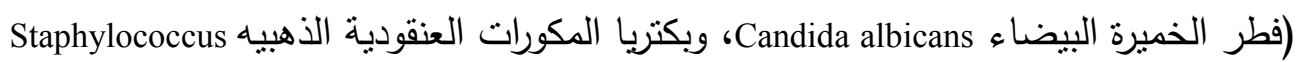

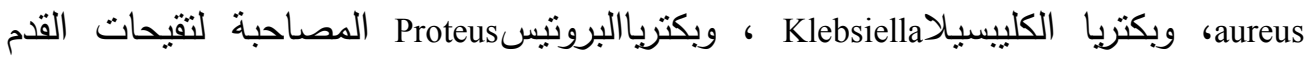

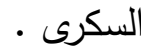




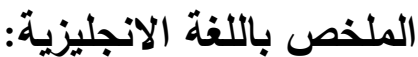

In this work we aimed to design and make a sock treated with Indian Costus and to study its antibacterial and antifungal activity against diabetic foot infections.

We studied the effect of Indian costus treated tissue on bacterial as Staphylococcus aureus, klebsiella and Proteus .Also, we studied the antifungal activity of Indian Costus treated tissue. We used several dilutions of Indian Costus $\%{ }^{\circ}, \% 1 \cdot$, and $10 \%$ dissolved in DMSO (Dimethyl Sulphoxide) and tested its antimicrobial activity against bacteria as Staphylococcus aureus, Klebsiella ,Proteus and fungi as candida albicans.

We found that $\% 10$ concentration of Indian Costus have a good antibacterial and antifungal activity compared to ${ }^{\circ}$ and $\% 1 \cdot$.

In conclusion, our work provide an opportunity to design and make an Indian Costus treated Sock for the care of diabetic foot to protect against bacterial and fungal infections. 


\section{المقدمة و المشكلة البحثية:}

السكرى من الامراض الأكثر إنتشارا فى العصر الحديث وحسب الاحصاءات الحالية

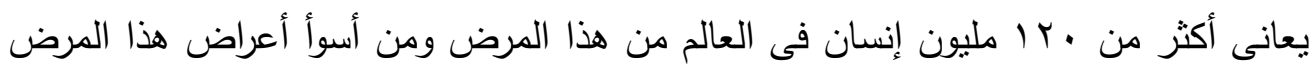

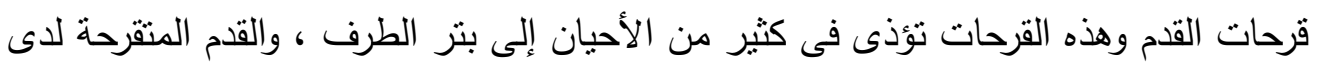

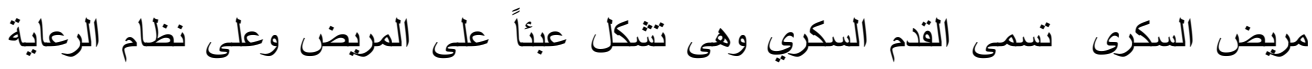
الصحية إضافة للكلفة المادية العالية الواقعة على عاتق المريض وأنظمة الرعاية الصحية. السكرى مرض مزمن يحدث بفعل عوامل بيئية وراثية وانتثار هذا المرض فى العالم وقد

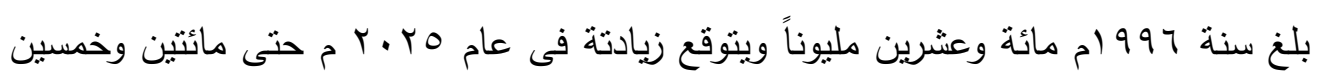
مليونا وذلك بسبب طول العمر والبدانة ونمط الحياة المريح وأنواع الاغذية المتبدلة. بدأت فى الأونة الاخيرة دعوة للعودة إلى الطبيعة من أجل صحة أمنة وذلك من خلال التطييب بالأعشاب للنقليل من الأخطار الناتجة عن الإفراط في إستخدام العقاقير الطبية . أرشدنا رسول البشرية سيدنا محمد علية الصلاة والسلام إلى التداوى بالقسط الهندى ولقد وقف العلم الحديث مبهورا امام مفردات الطب النبوى ونتائجه ومن ذللك ما أوصانا به رسولنا صلى الله عية وسلم (إن أمتل ما تداويتم به الحجامة والقسط الهندى ) (الاعجاز العلمى $(r \cdot) \cdot$ :

وللاقشة الغير منسوجة أهمية كبيرة فى مجالات عدة وهى تعتبر أرخص بكثير من الاقمشة المنسوجة لسرعة انتاجها وقلة تكلفتها فقد تعددت مجالات استخدامها ومن أهمها

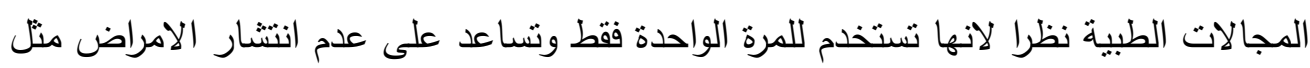
البكتريا والفطريات.

ومن خلال ما سبق يمكن تحديد مشكلة البحث فى الاجابة على التساؤلات الاتية: 1-ما مدى مساهمة المعالجة المقترحة فى انتشار الكائنات الدقيقة (البكترياوالفطريات) التى

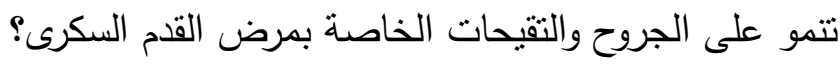
ץ-الى مدى يحافظ التصميم المقترح للجورب على خواص الاداء الوظيفى للقدم السكرى؟ 
1-دراسة تأثثر معالجة الأقمشة الغير منسوجة بمواد طبيعية وأمنة للقضاء على بعض أنواع البكتريا والفطريات.

ץ-تصميم جورب لمرضى القدم السكرى معالج ضد البكتربا والفطريات التى تصيب القدم.

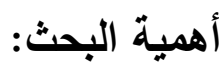

ا-إستخدام مواد آمنة لمعالجة الأقشة الغير منسوجة بتكلفة إقتصادية منخفضة. ץ-المساهمة فى الخطة العلاجية لمريض القدم السكرى وتقليل إنتشار بعض انواع البكتريا

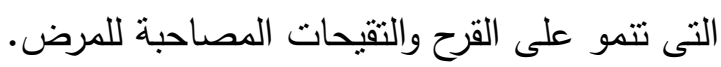
منهج البحث:

المنهج التجريبى:المنبع فى إجراء معالجات الاقمشة الغير منسوجة بمواد طبيعية آمنة

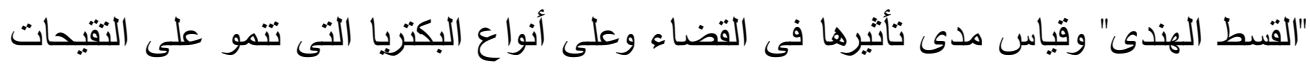
والجروح المصاحبة لمريض القدم السكرى. فروض البحث:

معالجة الاقمشة الغير منسوجة بالقسط الهندى لها تأثير ضد بعض أنواع البكتريا

$$
\begin{aligned}
& \text { والفطريات التى تصاحب القدم السكرى القئه } \\
& \text { الاطار النظرى }
\end{aligned}
$$

تكمن خطورة السكرى فى اختلاطاته وأثندها قرحات القدم التى تؤدى لبتر القدم لذا نجد

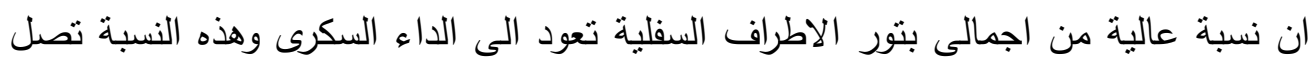
الى • •-. > \% اذا علينا معالجة قرحات القدم وقبل ذلك علينا معرفة أكثر الاسباب المؤدية

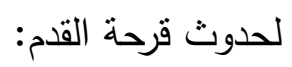

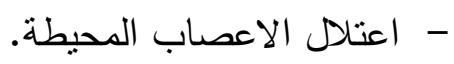

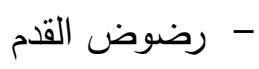
- تشوهات القدم الولادية والتشوهات التى يحدثها فقدان الحس فى الاقدام اذ لا يشعر مرضى السكرى بالرضوض الصغيرة المتكررة والتى تؤدى فيما بعد ذلك لتدمير القدم. لتهات التهات 
وفى انحاء العالم نجد تتوعا فى إصابات القدم وذللك تبعا للظروف الاجتماعية والاقتصادية وحسب معايير العناية بالقدم وبالاحذية المناسبة للمرضى السكريين فالاحذية غير المناسبة والنقص فى الاحذية يؤهب لحدوث رضوض تحدث قرحة القدم.

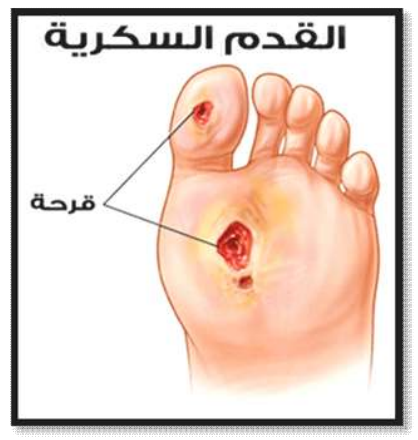

أولا- اعتلال الاعصاب السكرى Diabetic Neuropathy: هو عبارة عن وجود أعرض وعلامات خلل فى وظيفة عصب محيطى لدى المرضى

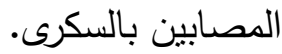

وقد اثتتت الدراسات ان فقدان الفحص هو تتبؤ كبير على قرحات القدم لذلك من الاهية بمكان فحص اقدام جميع مرضى السكرى دوريا عصبيا. ثانيا- أمراض الأوعية الدموية المحيطية والسكرية:

المرض الوعائى الدحبطى يشكل أهم عامل فى تحديد إنظار قرحة القدم السكرى. وتكون

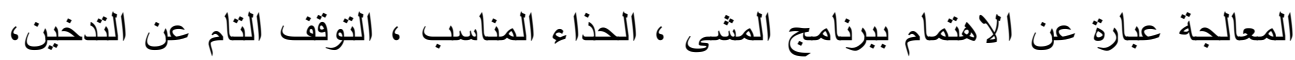

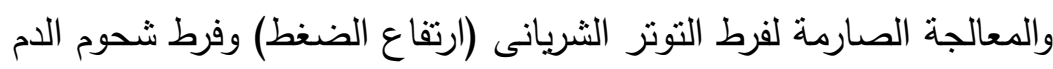

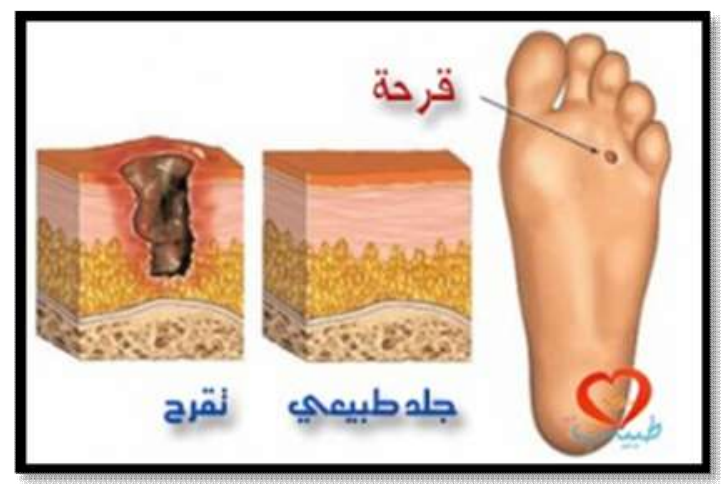




\section{ثالثا- نقص التروية الوعائية المزمن ويعرف بمعيارين هما :}

1-ألم الراحة الناجم عن نقص التروية المستمر والذى يحتاج للمسكنات لأكثر من أسبوعين ץ-ثقرح أو تموت القدم مع ضغط إنقباضى عند الكاحل أقل من •. مم زئبق وعند الأصبع

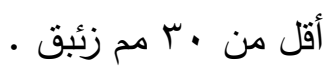

r-هناك عوامل خطورة بإيقافها ننقص نسبة خطر الموت وخطر البتر وهى :

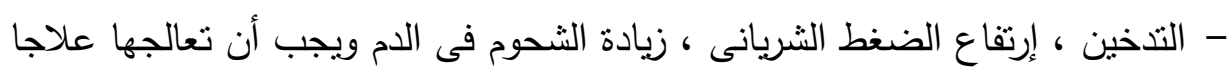

$$
\text { هجوميا }
$$

- - إعطاء جرعة منخفضة من الأسبرين يخفض من الأصابة بمرض الوعاء المحيطى - - برامج المشى ويستحسن فى العرج المتقطع مع مراعاة الحذاء الملائم رابعا -العوامل الخارجية والداخلية التى تؤدى إلى تقرح القدم:

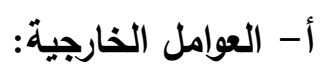

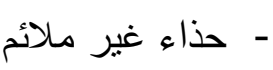
- - السير حافى - - -

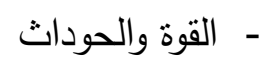

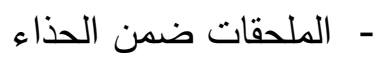

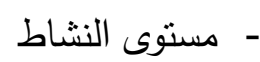

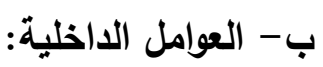

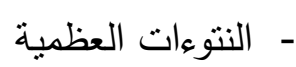
- نشوة المفصل - - إجراء جراحة قدم حديثة

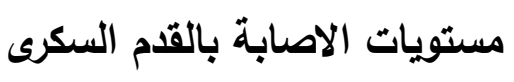

المستوى الاول : وجود المسببات الاساسية للمرض وأعرضها بالقدم بدون أى علامات عضوية المستوى الثانى : وجود علامات لاصيابات سطحية لا تتعدى طبقة الجلد يفترض فيها الثفاء الكامل او على الاقل عدم التذهور مع بدء العلاج الطبى المناسب. 
المستوى الثالث : وجود علامات لاصابات مؤثرة تهدد بفقدان القدم أو الطرف كلة على ان

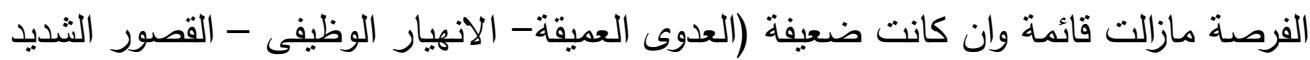
فى الثرايين ) المستوى الرابع : وجود علامات لاصابات ساحقة لا يفترض معها وجود فرص لانقاذ القدم

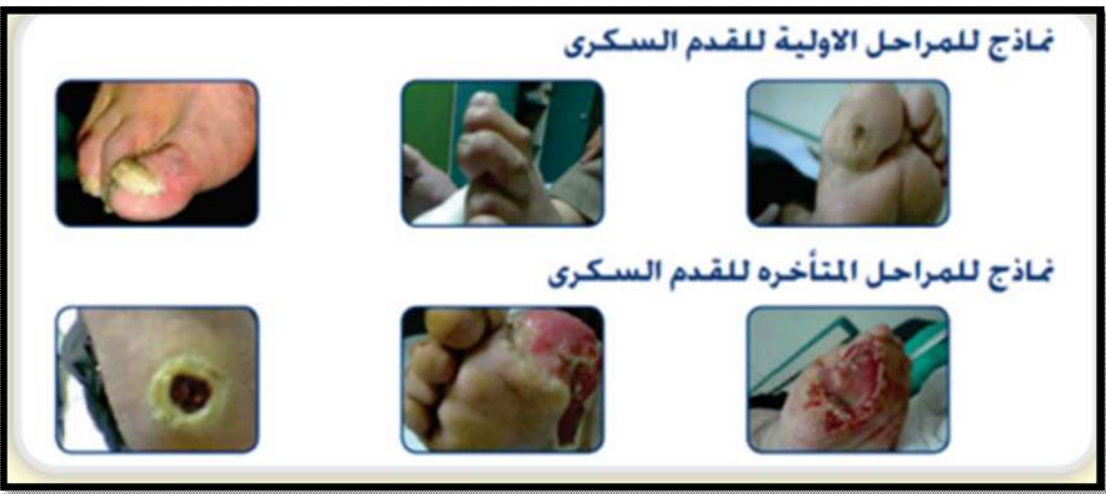

(العدوى الثاملة أو النافذة - الانهيار الوظيفى التام - الغرغرينا ) إجراءات الوقاية من المرض:

1-الفحص الدورى لقدم وحذاء المريض خلال الزيارة الدورية . r-العناية الوقائية بالقدم والحذاء

$$
\text { - معالجة الاقدام - الاحذية الصحية }
$$

ץ-فحص المريض المصاب من قبل عدة متخصصين . ع -التشخيص المبكر لامراض الأوعية المحيطية.

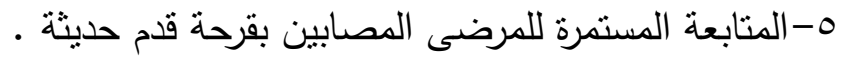
1-تسجيل البتور وقرحة القدم.

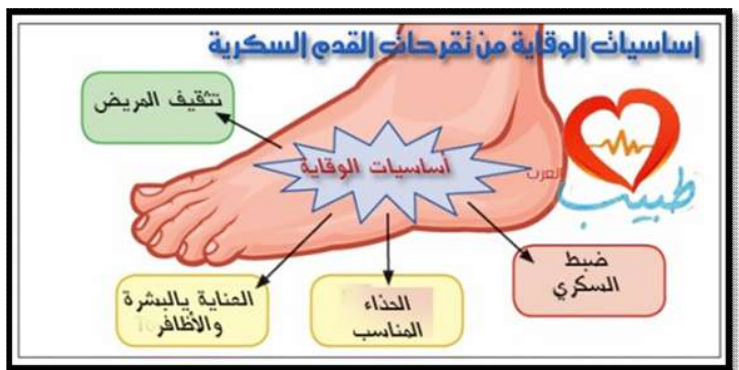




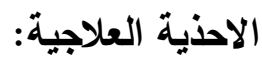

أحذية صممت لرفع الضغط بشكل كامل عن القرحة فالقرحة لن تشفى حتى يزال عنها التحمل الميكانيكى والمريض المصاب بقرحة القدم يلزم عدم السماح له بالسير دون التنخل

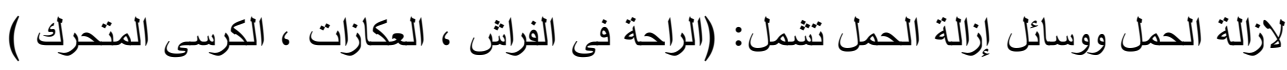
الأحذية الواقية:

وهى التى تحمى القدم من الضغوط قبل حدوث التقرح وهى ذات أهمية كبيرة فى الوقاية من القرحة ويجب الا يعودوا المرضى إلى استعمال الأحذية التى سبق وأن سبيت لهم حدوث القرحة سابقا.

وتوصف الأحذية لمرضى السكرى ان تكون واضحة نسبيا وتركز على المطابقة والتبطين وتوصف بالاعتماد على تشوه قدم المريض ومستوى نشاطة.

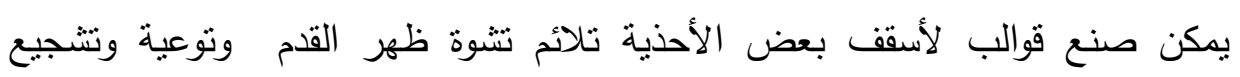

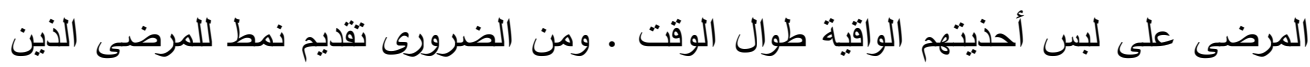

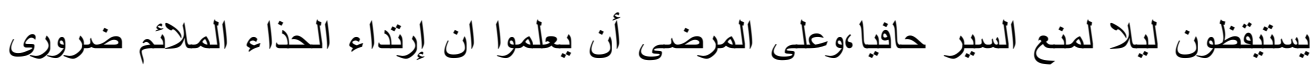

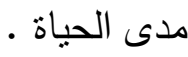

قياس أبعاد القدم Foot measurement: يتم قياس أبعاد القدم بإستخدام العديد من الطرق منها القياس اليدوى باستخدام أدوات

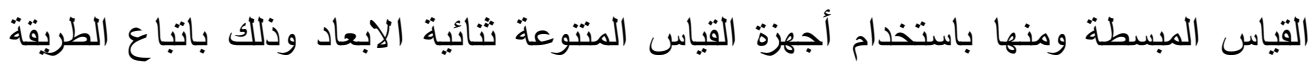

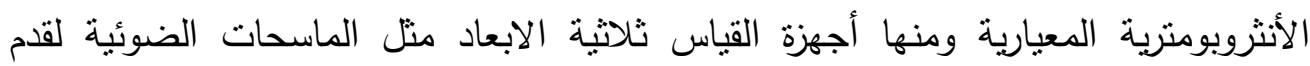
والكاميرات الرقية كما بتم قياس حجم القدم أيضا عن طريق تطبيق ثقنية خاصة. (Ravinra,Goonetilleke:2009)

\section{طريقة القياس ثلاثية الأبعاد:}

وتعد أكثر أساليب قياس القدم المنطورة وتساعد تقنية مسح الجسم ثلاثية الابعاد الثركات فى أن تحسن مصنوعاتها سواء المصنوعة بكميات كبيرة أو حتى محدودة الانتاج

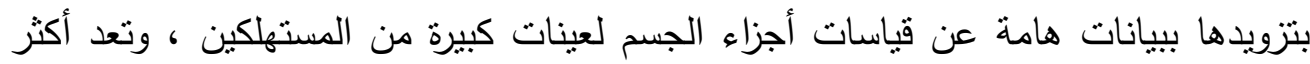
أنظمة معايرة القياسات تقدما لاستتادها على معلومات محات محدودة ودقيقة جدا ولم تكن أساليب 
الدراسة التى اتبعت او الاجراءات التقليدية تسدح بالحصول على قياسات يمكن الاعتماد عليها فى التصميم والانتاج.(www.shomaster.co.uk)

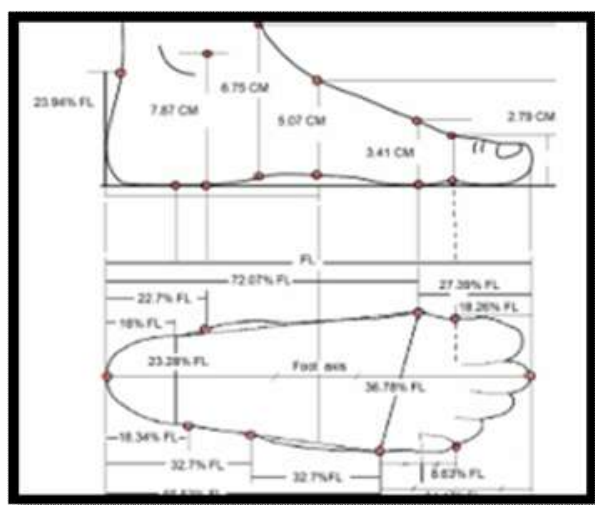

شكل يوضح النسب للقياسات الأنثروبو مترية للقدم البشرية

"Foot Length " تعنى الطول الكلى للقدم FL * تعنى القياس بالسنتيمنر CM* foot axis *

القسط الهندى نوعان الأول يسمى بالبحرى والثانى بالهندى وورد فى الحديث النبوى النى

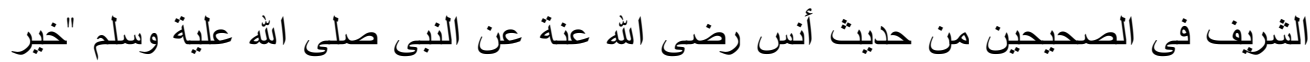

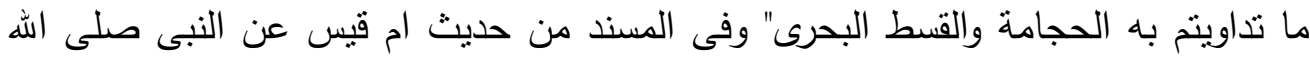

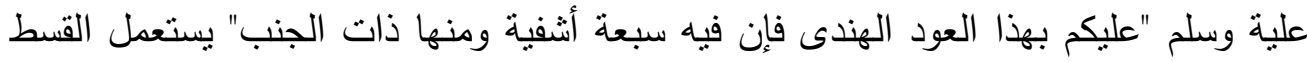

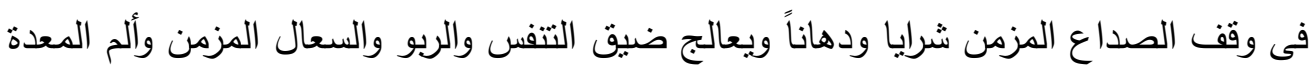

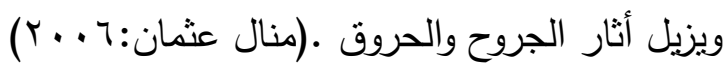

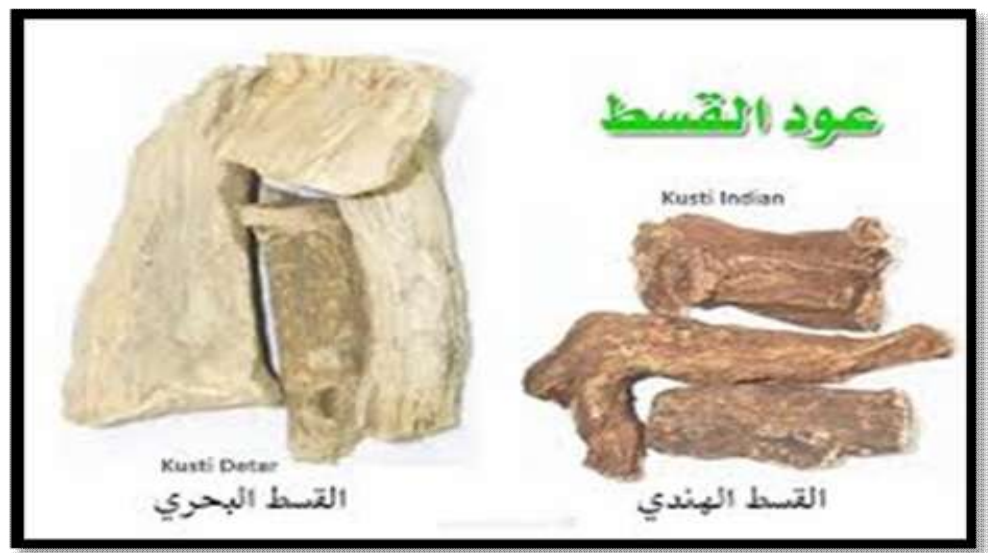


المواد الطبية فى القسط الهندى وطرق المعالجة:

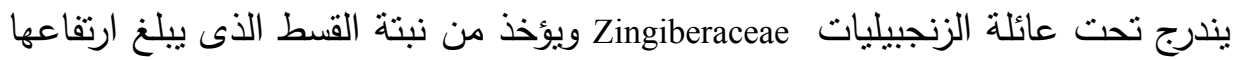

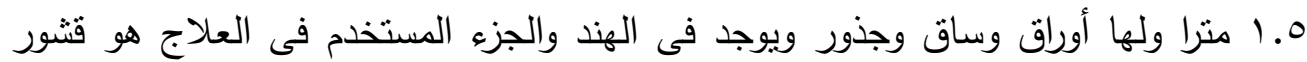

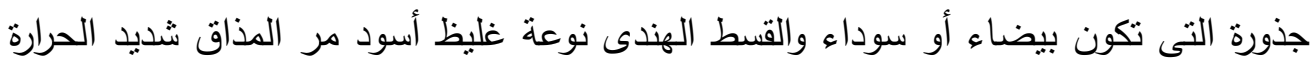

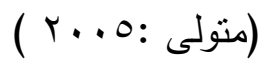
واستخدم فى هذه الدراسة جذور القسط الهندى ذو اللون البنى المائل إلى الاسود متوفرة

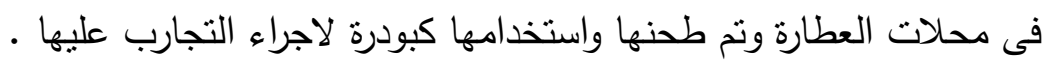

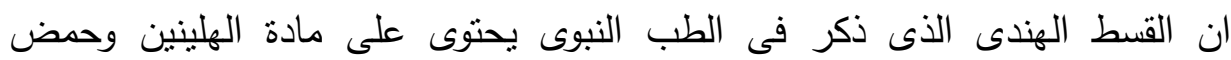

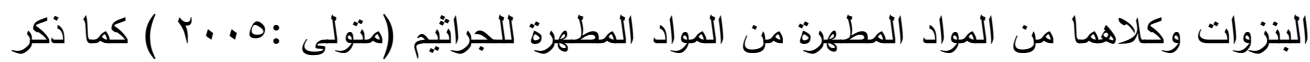

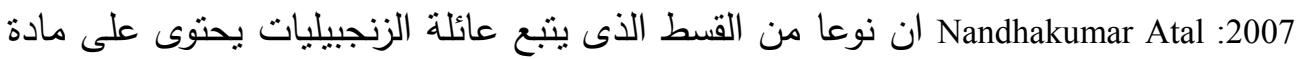
الميثانول المطهرة والقاتلة او المثبطة للاحياء الدقيقة الممرضة .

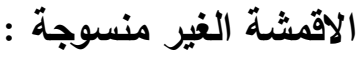

تعرف الاقششة غير المنسوجة بانها تركيب بنائى من الشعيرات الطبيعية او الصناعية

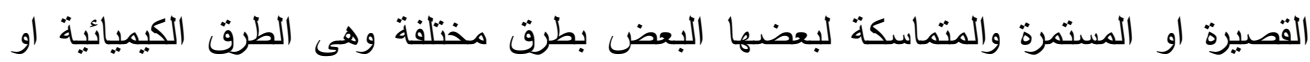
الحرارية او الميكانيكية ويتكون القماش الغير منسوج من ترابط الثعيرات بمادة لاصقة أو رابطة او بطرق

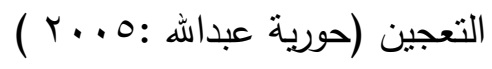

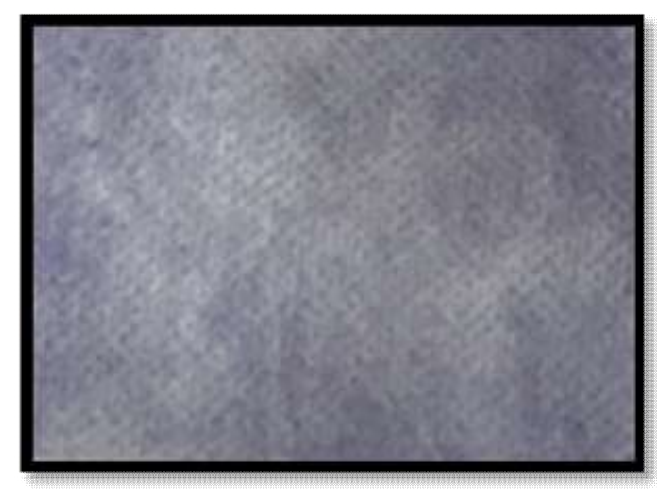

شكل يوضح الاقشة الغير منسوجة

الخواص الواجب توافرها فى الاقمشة الغير منسوجة :

يمكن تقسيم الخواص إلى طبيعية وتشمل: الوزن لحصيرة الثعيرات وامتصاص الرطوبة فئه

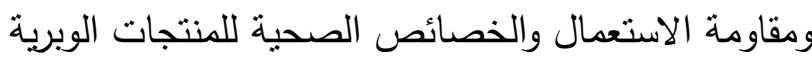

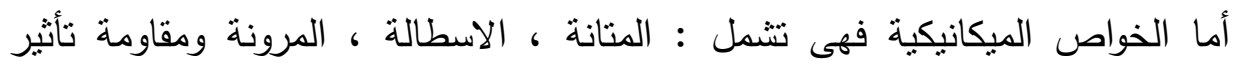

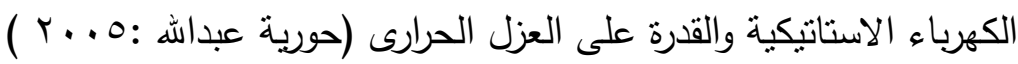


الهدف من معالجة الاقمشة بمواد مقاومة للبكتريا:

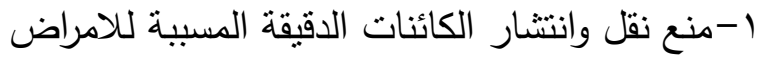

$$
\begin{aligned}
& \text { r-الحفاظ على خواص الاداء الوظيفى } \\
& \text { ب-التحكم فى نمو الميكروبات }
\end{aligned}
$$

ـ-تجنب انتقال العدى بواسطة الكائنات الدقيقة المسببة للامراض ه-حماية مرتديها لاغراض طبية او صحية او جمالية من البكتريا وفطريات الجلد والخمائر والفيروسات وسائر الكائنات الدقيقة الضارة

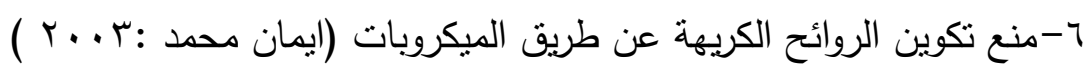

$$
\text { أوالا الخار التطبيقى مواد المعات والادوات: }
$$

القسط الهندى وهو عبارة عن أعشاب طبيعية يوجد على هيئة سيقان خشبية يمكن طحنها

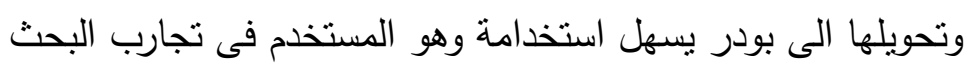

ب- القماش المستخدم : قماش غير منسوج من القطن مخلوط ببولى إستر بنسبة خلط

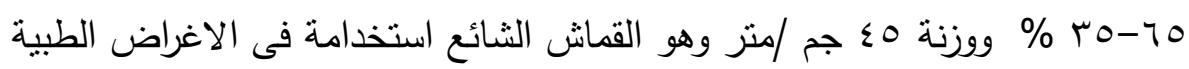

$$
\text { ت- العينات المستخدمة }
$$

عينه رقم 1: 0 \% من القسط الهندي مذابه في ثنائي مينيل السلفوكسيد

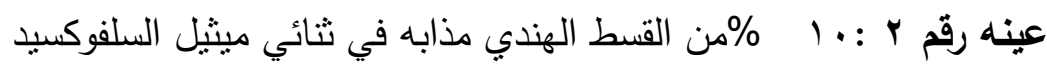

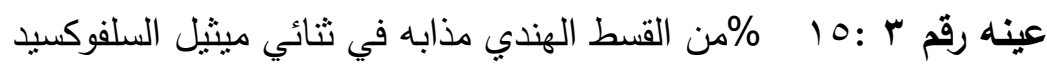

ث- البكتريا المستخدمة

- - بكتريا المكورات العنقودية الذهبيه -

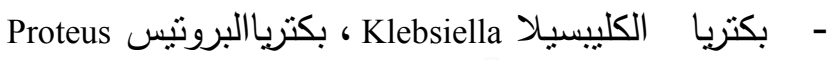

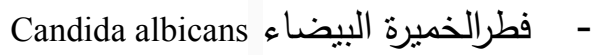

\section{ثاتيا اجراعات التجربة :}

تم معالجة الاقمشة الغير منسوجة بالقسط الهندى من خلال اذابتة فى ثثائي ميثيل

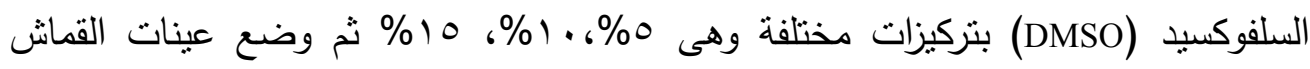
على الفطريات والبكتريا. 
ثالثا : تصميم الجورب :

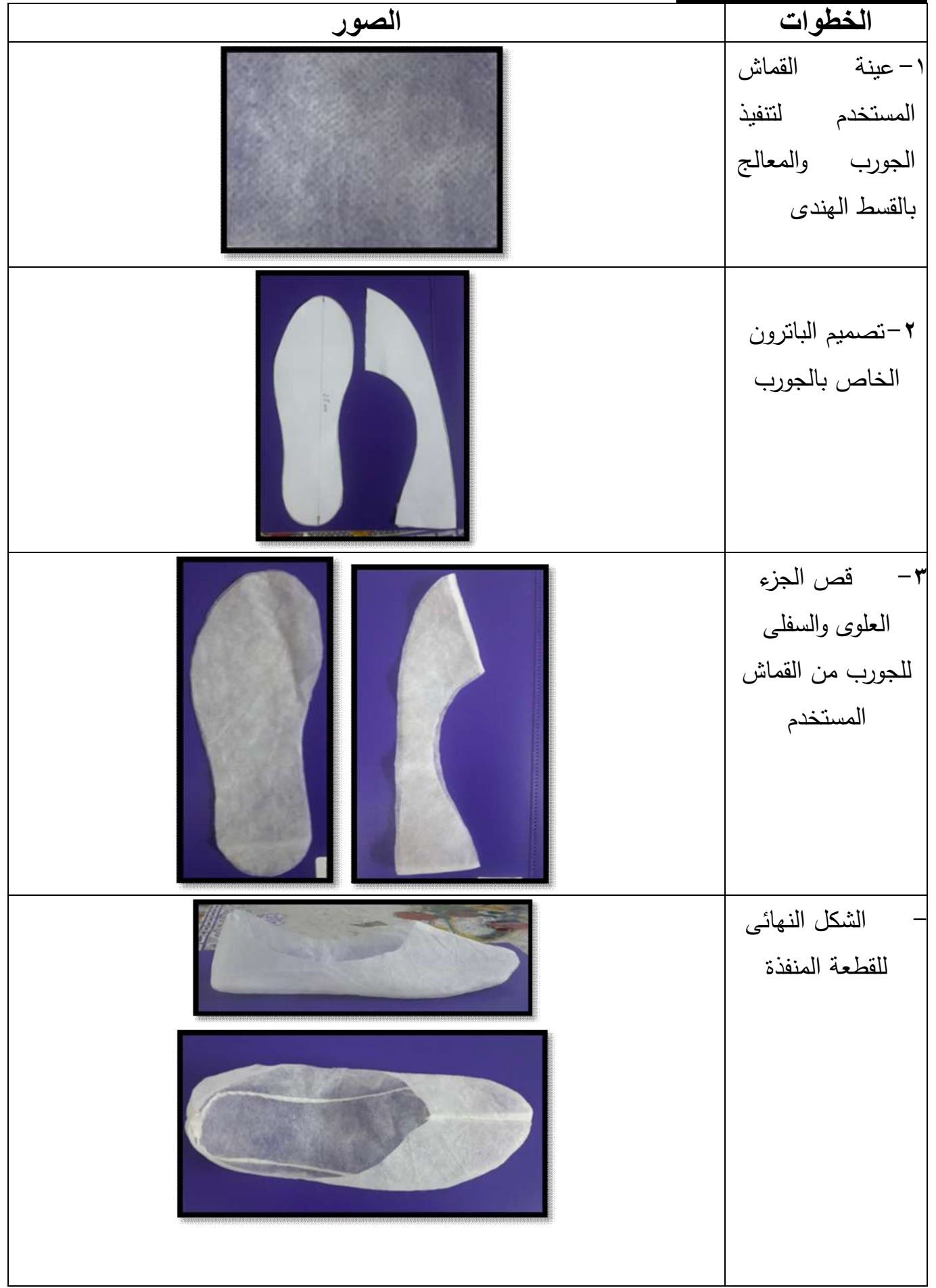


تم قياس مدى تأثير القسط الهندى وكانت النتائج كما موضح بالصور الاتية:

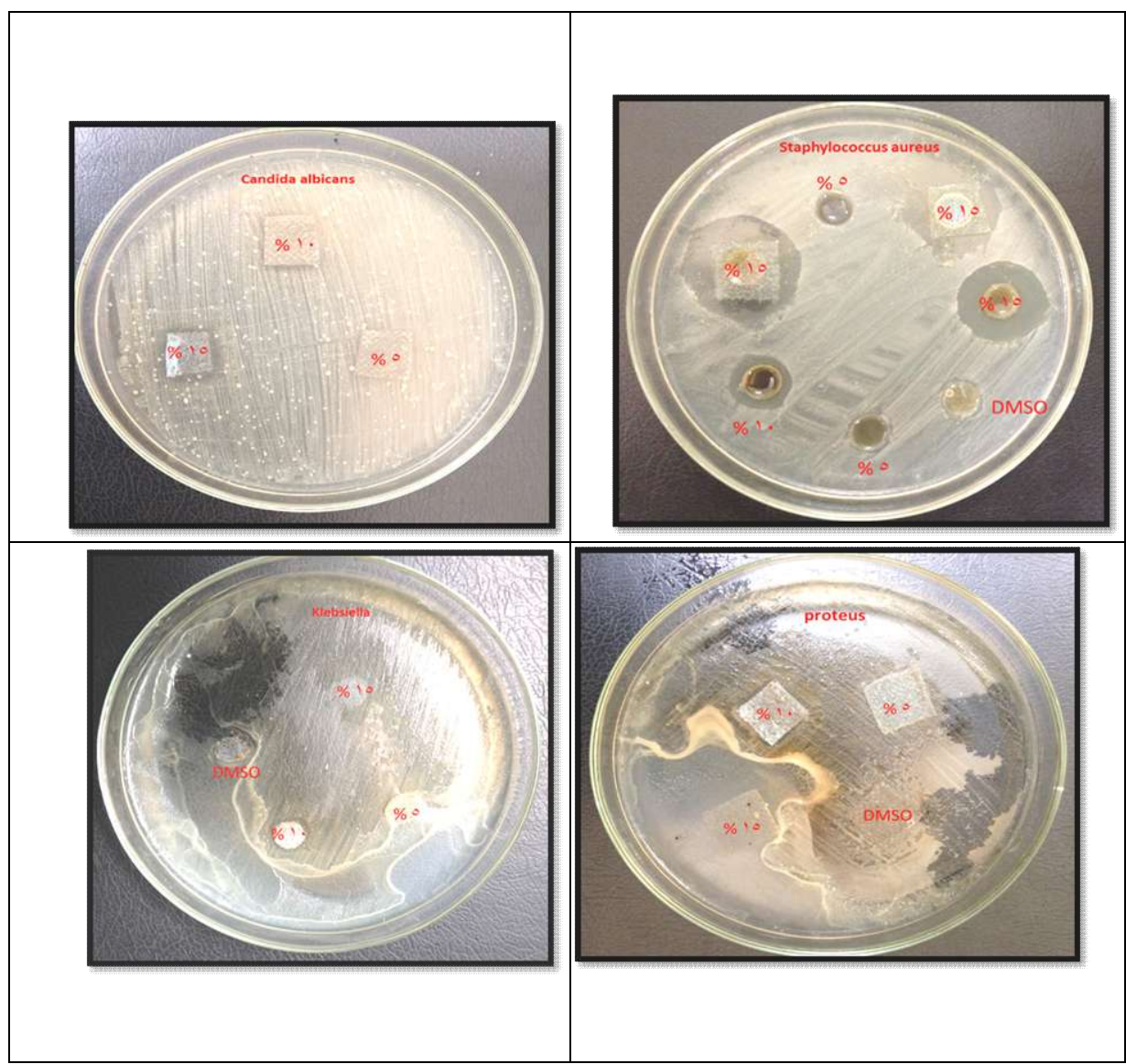

خامسا المعالجات الاحصائية:

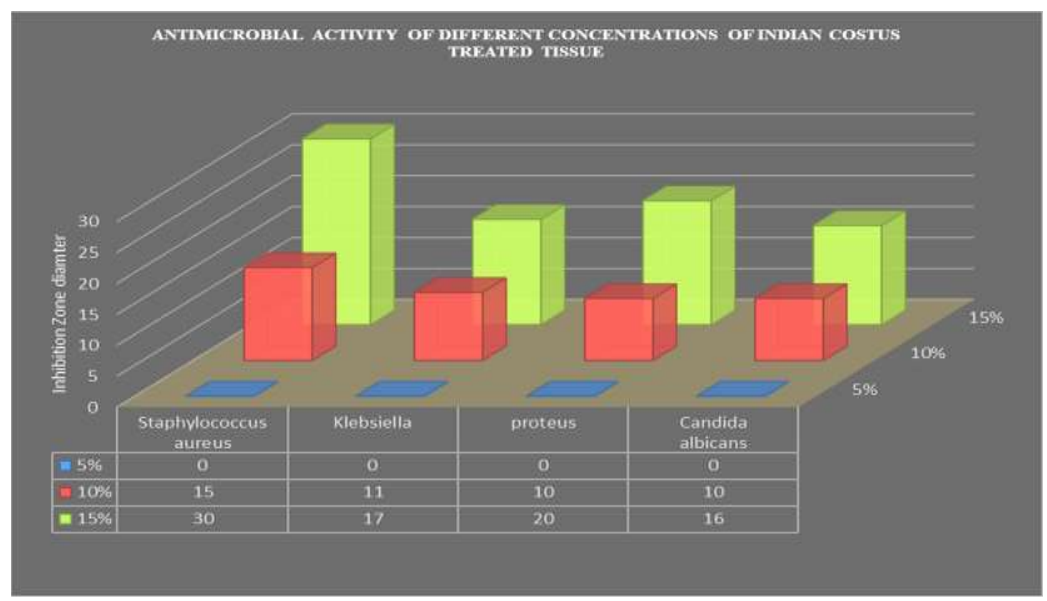


1-الاعجاز العلمى (• ( • ؟):"الهيئة العالمية للاعجاز العلمى فى القرأن والسنة " العدد Vr r- حورية عبداله تركستانى (0. r): "دراسة مدى تحقيق عاملى الامان والستر لملابس العمليات الجراحية "، مجلة الاقتصاد المنزلى ، جامعة المنوفية.

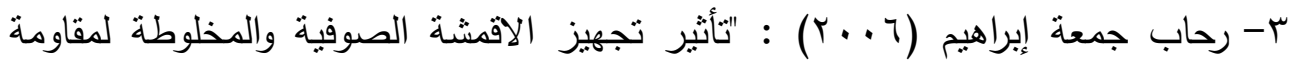

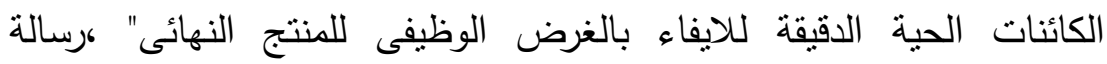
ماجستير ، كلية التربية النوعية ، جامعة طنطا. ع- إيمان محمد على (ץ . . ץ) : "تحسين خواص الضماضات الجراحية لتفى بغرض الأداء الوظيفى للاستخدام النهائى" ، رسالة ماجستير ، كلية الفنون النطيقية ، جامعة حلوان.

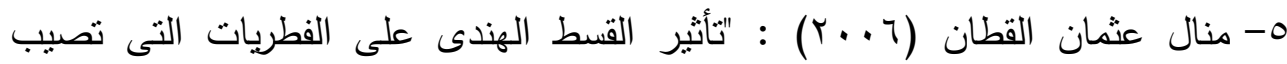
الجهاز التنفسى فى الانسان لاظهار الاعجاز العلىى للسنة النبوية "، كلية

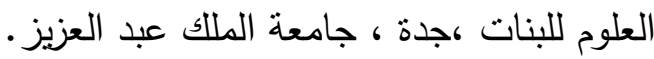

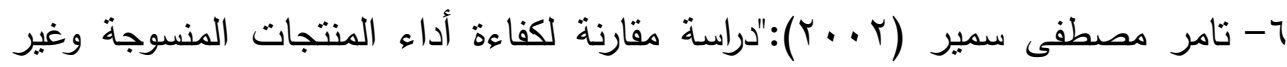
المنسوجة فى الاستخدام كأقمشة طبية" ، رسالة ماجستير ، كلية الفنون التطبيقية ، جامعة حلوان مانه

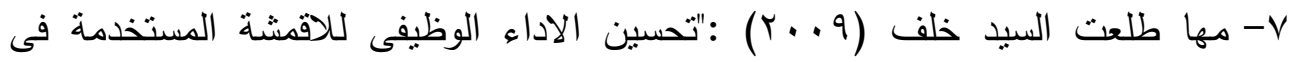

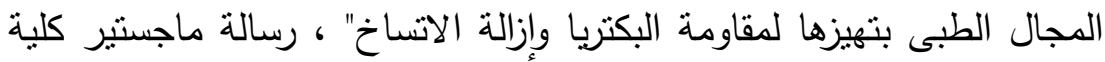

الاقتصاد المنزلى ، جامعة المنوفية.

8- Ravinra,Goonetilleke(2009):"Foot Anthropometry in Hong Kong"Hong Kong university of Science and Technology,Department of Industrial Engineering.

9-A. C. Scott, in: J. G. Collee, J. P. Duguid, A. G. Fraser, B. P. Marmion (Eds.), Mackie \& McCartney (1989)"Practical Medical Microbiology", Churchill Livingstone, Edinburgh,

10-A. Felten, B. Grandry, P. H. Lagrange and I. Casin, J. Clin. Microbiol., (2002)

11- W. Hewitt (Eds.), "Microbiological Assay An Introduction to Quantitative Principles and Evaluation", Academic Press, New York(1977) 